\title{
CURVE NEGOTIATION: IDENTIFYING DRIVER BEHAVIOR AROUND CURVES WITH THE DRIVER PERFORMANCE DATABASE
}

\author{
Anna Mikolajetz ${ }^{1}$, Matthias J. Henning ${ }^{2}$, Axel Tenzer ${ }^{3}$, \\ Robert Zobel $^{4}$, Josef F. Krems ${ }^{2}$ \& Tibor Petzoldt ${ }^{2}$ \\ ${ }^{1}$ Human-Factors-Consult, Berlin, Germany \\ ${ }^{2}$ Chemnitz University of Technology, Chemnitz, Germany \\ ${ }^{3}$ Ingenieurbüro Lange + Tenzer, Hannover, Germany \\ ${ }^{4}$ Volkswagen AG, Wolfsburg, Germany \\ Email address: matthias.henning@phil.tu-chemnitz.de
}

\begin{abstract}
Summary: Approximately one quarter of all accidents outside city limits occur while driving around curves, where assistance systems could prevent the driver from negotiating curves with excessive speed. This study argues that the parameterizing of a Driving Assistant System could be realized with data from realistic, noncritical driving behavior offered by Naturalistic Driving Studies. The Driver Performance Database presented in this study provides a tool for observing normal, noncritical driving behavior. The Database contains results from road tests with an instrumented vehicle that were carried out on public road traffic on a predetermined route, which was precisely measured in advance. In addition to vehicle state parameters, we also collected data concerning the driving environment and physiological information. With the Driver Performance Database it is possible to generate different facets of human driving behavior in a descriptive and normative way, which is illustrated by driver behavior in curve negotiation.
\end{abstract}

\section{INTRODUCTION}

Naturalistic Driving Studies (NDS) with instrumented vehicles generate a variety of data about driving behavior in critical and noncritical traffic situations. However, the proportion of critical and noncritical traffic situations is strongly unbalanced. For example, the 100-car Naturalistic Driving Study carried out by the Virginia Tech Transportation Institute (VTTI) showed that within 12 to 13 months of data collection and an overall of 2,000,000 miles traveled, only 15 police-reported and 67 non-police-reported crashes, which included low "g" events such as striking or running over curbs and parking blocks (some vehicles were involved in multiple crashes), 761 near-crashes and 8,295 incidents occurred (Dingus et al., 2006). This leads to an incident rate of about $4.6 * 10^{-3}$ incidents $/ \mathrm{mi}$. Applying the number of incidents to the number of hours driven during this study $(\mathrm{H}=42,300)$, a rate of one incident approximately every 4.6 hours can be determined.

The incident rate shows that a mere concentration on the driving behavior in critical traffic situations invalidates a great part of data. However, these data that describe driving behavior in noncritical situations in every-day road traffic are very valuable. Driver Assistant Systems are usually only beneficial if they are geared to the boundaries of average driving behavior. This ensures that drivers are neither under challenged nor overstrained. Assistant systems parameterized through real data on driving behavior minimize the number of false alarms in 
noncritical as well as missing alarms in critical situations, leading to a broad acceptance of the system by a large number of drivers.

An inverse approach can be beneficial to describing critical driver behavior with all NDS-data. We used statistical analysis of data on noncritical driver behavior to describe range and limits of situation related driver behavior data in noncritical situations. The compiled results can be used as a decision criterion to differentiate noncritical from critical driver behavior.

In this study driver behavior around curves was selected to assess the contribution of the Driver Performance Database to defining noncritical driver behavior within the design of a driver assistant system for curve negotiation (curve assistant). According to the German Federal Statistical Office (Statistisches Bundesamt, 2007), 26\% of accidents on German roads outside city limits in 2006 occurred while driving around curves, often caused by inappropriate driver behavior (e.g., excessive speed). These accidents caused $36 \%$ of the casualties outside city limits. Consequently, curves form the highest risk for drivers compared to other accident sites. Further, drivers rate narrow curves as the most dangerous element of the road and they are associated with the greatest perceived fear (Ellinghaus \& Steinbrecher, 2003). These results indicate the potential to enhance safety with the implementation of a curve assistant. A curve assistant could facilitate curve negotiation by recommending a curve-specific speed as well as when to decelerate, depending on vehicle speed while approaching a curve.

\section{METHOD}

In order to collect and evaluate sample amounts of data with NDS, the Volkswagen AG Group Research developed a Driver Performance Database between the years of 2003 and 2005. It is used for the consistent recording of data categories - driver, vehicle, environment - throughout the test, as well as for statistical and analytical evaluation under different, not predefined questions. This methodology makes use of three elements: a predefined reference route, an instrumented vehicle, and a relational data base as an intelligent medium for storage and evaluation of the collected data (Tenzer, 2004).

\section{Reference route}

A differential GPS (Niemeier \& Thomsen, 2003) was used to measure a circuit of approximately 55 kilometers of public road near Wolfsburg (Lower Saxony, Germany). This sample contained the curves analyzed in this study (see Figure 1). The measurement included mapping out all traffic devices (e.g., highway striping, center lines, stop lines, closed areas) in type and location as well as determining all traffic signs' position and angle toward the road. Furthermore, all intersections and the surrounding area reaching 30 to 50 meters into each of the cross-streets were mapped out, as well as traffic devices and traffic signs. The measurement data were stored in the database as high-precision Gauss-Krüger-coordinates. 


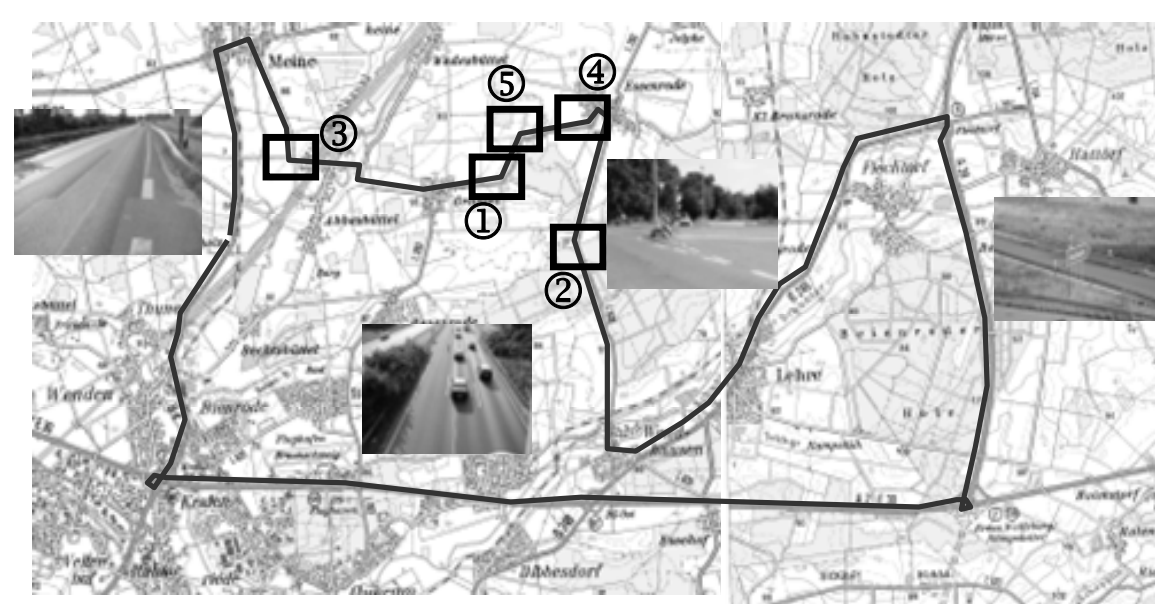

Figure 1. Reference route of the Driver Performance Database and the analyzed curves

\section{Instrumented vehicle}

Driver behavior was recorded with the ViewCar of the German Aerospace Center in Brunswick, Germany. A further description of the ViewCar can be found in (Suikat, Rataj, Schäfer, \& Rollke, 2003).

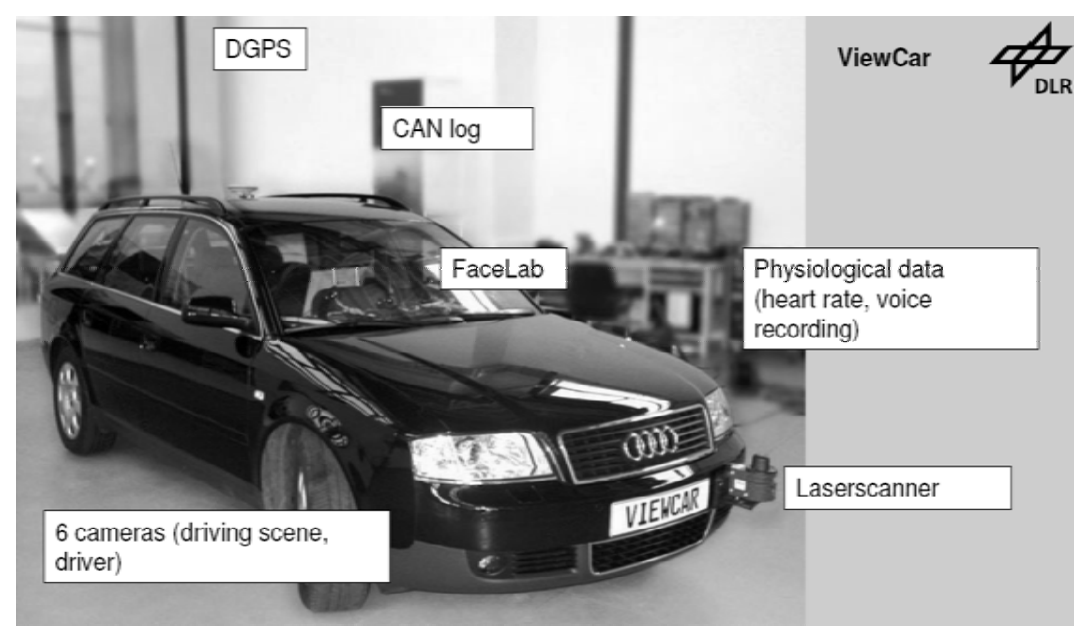

Figure 2. ViewCar

The vehicle was equipped with a positioning system. Drivers' actions (onset of brake and accelerator, steering, gaze behavior), physiological data (e.g., heart rate), and vehicle state parameters (e.g., speed, acceleration) were recorded using various sensors and the CAN-bus. A list of additional sensors is found in Table 1. 
Table 1. List of sensors that are installed in the ViewCar

\begin{tabular}{|c|c|c|}
\hline Sensor & Task & Supplier \\
\hline Laser scanner & $\begin{array}{l}\text { Identification of objects in front of the } \\
\text { vehicle }\end{array}$ & IBEO Automobile Sensor GmbH, Hamburg \\
\hline Cameras & $\begin{array}{l}\text { Video recording of driver and driving } \\
\text { scene }\end{array}$ & Aglaia GmbH, Berlin \\
\hline Facelab-System & Gaze tracking & Seeing Machines, Canberra (Australia) \\
\hline Physiolog & $\begin{array}{l}\text { Physiological data recording (heart } \\
\text { rate, voice) }\end{array}$ & GEFATEC GmbH, Tiefenbach \\
\hline Positioning system & Vehicle position & iMAR GmbH, St. Ingbert \\
\hline Lane detection & & ADCS GmbH, Lindau \\
\hline
\end{tabular}

The geographical position of the vehicle was provided by a differential global positioning system. In areas with poor signaling (forest, tall buildings, and alleys) position data was adjusted by an inertial navigational system. All recorded data were time stamped and saved in the database.

\section{Driving tests}

Driving tests were conducted in daily traffic on the reference route under various traffic and weather conditions. Subjects were 6 males and 5 females. They ranged from 23 to 78 years of age and had from 6 to 44 years of driving experience. Each subject completed the course 5 to 6 times on different days in the periods July to November 2004 and March to April 2005, except one subject who dropped out after 2 sessions. At each session subjects drove the course in both directions. They were instructed to drive as they normally would; the experimenter gave directions to follow the course but no further instructions or advice was given. The driver was responsible for the car and all fines. Furthermore, no additional tasks were given to the driver and no special settings had been created. The purpose was to collect data on "normal" driver behavior.

\section{Driver Performance Database}

The driver performance database is a relational database. The design and development team balanced the tasks of creating an open database system with an unlimited data capacity making it extendable to future tasks. Within the framework of database development, a data model was set up according to the requirements of the reference track and driving tests. All sensor data gathered from the instrumented vehicle received a common time stamp. Sensor data and data from the reference track had been linked by geographical position (i.e., easting and northing) of the car. The outcome is a database in which data as an indicator for driver behavior is not only saved by its characteristics but also by the situational context. 


\section{Data analysis on the example of negotiating curves}

Five curves on rural roads were selected for analyzing deceleration behavior prior to curves and characteristic curve speeds. As participants drove the course in both directions, each curve was negotiated as a left and right turn. Curve characteristics are listed in Table 2. Curve 3 (right turn) and curve 4 (right turn) were excluded from analysis because low vehicle speed and thus no deceleration were expected due to the city situated prior to that curves.

Table 2. Curve Characteristics

\begin{tabular}{lllll}
\hline Curve & Radius $(\mathrm{m})$ & Length $(\mathrm{m})$ & Analyzed directions & Signage \\
\hline 1 & \pm 80 & 52 & left/right & curve warning (left only) \\
2 & \pm 70 & 41 & left/right & speed limit: $40 \mathrm{~km} / \mathrm{h}$ (left only) \\
3 & \pm 79 & 111 & left & - \\
4 & \pm 54 & 38 & left & - \\
5 & \pm 27 & 38 & left/right & curve warning (right only) \\
\hline
\end{tabular}

Figure 3 shows an example data set analyzed during curve negotiation. Prior to a curve, the driver releases the accelerator which results in a reduction of speed, followed by application of the brake pedal and a greater reduction in speed. Figure 3 also indicates the values that were assessed from speed, accelerator, and brake pedal profiles to characterize curve negotiation behavior. According to the definition of characteristic curve speed by Lippold (1997) minimal curve speed was chosen to characterize the possible speed associated with the curve characteristics. Speed differences from speed at the beginning of deceleration and breaking to minimal curve speed were determined. The mapping of the vehicle's position data to the gauged route allowed a precise determination of the vehicle's distance to curve while releasing the accelerator and applying the brake pedal.

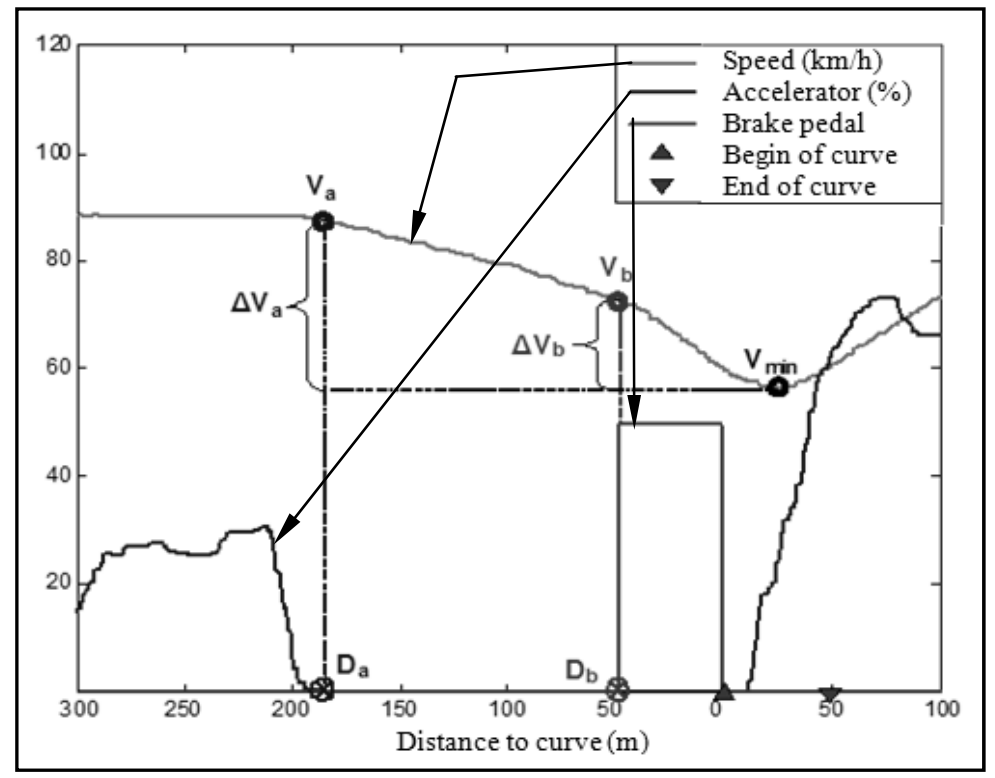

Figure 3. Assessment of speed (V), distance to curve (D), speed difference $(\Delta V)$ at the beginning of deceleration (a) and braking (b), and the curve speed minimum $\left(V_{\text {min }}\right)$ 
Only a portion of the data was available at the time of analysis. From the analyzable 379 curve negotiations, only those performed on dry road surfaces were selected. This resulted in a total of 337 curve negotiations analyzed.

\section{RESULTS}

The results for minimal curve speed are displayed in Figure 4a. Individual speed profiles as a function of curve characteristics were derived from the means in minimal curve speed for every subject. They indicate a consistently higher and lower speed level, respectively, for individual subjects compared to the average level throughout different curves. With an increasing change of direction provoked by the curve the observed minimal curve speed and its variability decrease.
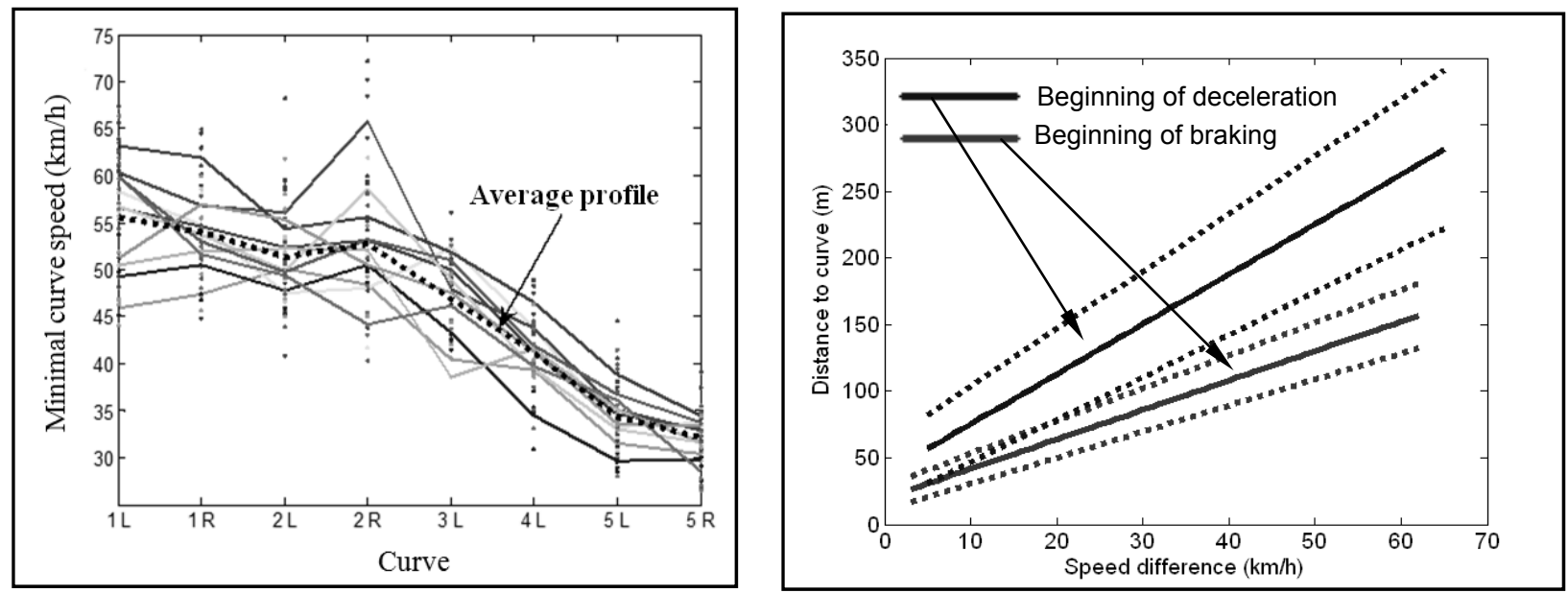

Figure 4. Individual speed profiles as a function of curve characteristics (left hand side; see Table 2 for curve characteristics); Prediction of distance to curve at the beginning of deceleration and braking from speed difference (right hand side; continuous lines indicate regression lines, dashed lines indicate the borders of the 95\% confidence interval)

Speed differences and distance to curve were incorporated into a regression analysis to provide a prediction model for the specific distance to a curve where drivers begin to decelerate and brake prior to a curve. Figure $4 \mathrm{~b}$ displays the regression slope for the beginning of deceleration $\left(\mathrm{D}_{\mathrm{a}}=\right.$ $3,75 \Delta \mathrm{V}_{\mathrm{a}}+37,79$ ) with the associated limits of the $95 \%$ confidence interval (upper limit: $\mathrm{D}_{\mathrm{a}}=4,31 \Delta \mathrm{V}_{\mathrm{a}}+60,79$; lower limit: $\left.\mathrm{D}_{\mathrm{a}}=3,19 \Delta \mathrm{V}_{\mathrm{a}}+14,80\right)$ and the regression slope for beginning to brake $\left(\mathrm{D}_{\mathrm{b}}=2,21 \Delta \mathrm{V}_{\mathrm{b}}+19,73\right)$ with the associated limits of the $95 \%$ confidence interval (upper limit: $\mathrm{D}_{\mathrm{b}}=2,46 \Delta \mathrm{V}_{\mathrm{b}}+28,53$, lower limit: $\mathrm{D}_{\mathrm{b}}=1,96 \Delta \mathrm{V}_{\mathrm{b}}+10,92$ ).

\section{CONCLUSION}

Noncritical driving behavior is a data source to parameterize driver assistance systems. In most cases assistance systems will be triggered when drivers exceed prescriptive limits. These limits can be derived from "normal", noncritical behavior from a large sample of drivers within an NDS. The methodology introduced here allows a description of driver behavior with the driver performance database, as demonstrated with the example of driver behavior within curve negotiation. The results show that there is a range of normal, noncritical driving behavior while negotiating curves. This driving behavior can be described by a mathematical equation, in our 
case a regression formula. However, the results obtained in this example should be validated by further data from studies on noncritical driving behavior and critical events. A fruitful source of data was obtained from the 100-car study by Dingus et al., (2006).

\section{ACKNOWLEDGEMENTS}

This research was funded by the Volkswagen AG, Wolfsburg, Germany, and conducted with the help of the German Aerospace Center (DLR), Brunswick, Germany.

\section{REFERENCES}

Dingus, T. A., Klauer, S. G., Neale, V. L., Petersen, A., Lee, S. E., Sudweeks, J., et al. (2006). The 100-Car Naturalistic Driving Study, Phase II (Results of the 100-Car Field Experiment). (DOT HS 810 593). National Highway Traffic Safety Administration.

Ellinghaus, D., \& Steinbrecher, J. (2003). Fahren auf Landstraßen.Traum oder Alb-traum? Untersuchung zum Fahrverhalten und Fahrvergnügen von Pkw-Fahrern auf Landstraßen. Köln/Hannover: UNIROYAL-Verkehrsuntersuchung (28).

Lippold, C. (1997). Weiterentwicklung ausgewählter Entwurfsgrundlagen von Landstraßen. Unpublished Dissertation, Technische Hochschule Darmstadt.

Niemeier, W., \& Thomsen, S. (2003). GPS in der Unfallforschung. Proceedings of the DGONSymposium Positionierung und Navigation POSNAV. Dresden, Germany.

Statistisches Bundesamt (2007). Unfallgeschehen im Strassenverkehr 2006. Wiesbaden: Statistisches Bundesamt. Retrieved 15.12.2007, from https://wwwec.destatis.de/csp/shop/sfg/bpm.html.cms.cBroker.cls?cmspath=struktur,vollanzeige.csp\&ID $=1020767$

Suikat, R., Rataj, J., Schäfer, H., \& Rollke, R. (2003). ViewCar - den Fahrer verstehen. Proceedings of the Conference Optische Technologien in der Fahrzeugtechnik. Düsseldorf: VDI Verlag.

Tenzer, A. (2004). Die Fahrerleistungsdatenbank der Volkswagen AG als Werkzeug zur Beobachtung von Fahrerverhalten. Proceedings of the 21. VW/VDI-Gemeinschaftstagung „Integrierte Sicherheit und Fahrerassistenzsysteme“. Wolfsburg, Germany. 